\title{
A GARANTIA DO DIREITO À EDUCAÇÃO BÁSICA NO BRASIL: O ATIVISMO JUDICIAL COMO MEDIDA ASSECURATÓRIA DE DIREITOS FUNDAMENTAIS
}

\author{
Gabriela dos Santos Paixão
}

Faculdade de Direito da Alta Paulista. E-mail: gabrielapaixao@ @hotmail.com

\begin{abstract}
RESUMO
O Poder Judiciário tem assumido uma participação significativa na efetivação dos direitos fundamentais. $O$ exercício da função jurisdicional pautado nessa atitude que ultrapassa as funções típicas atribuídas ao Judiciário pode ser denominado como ativismo judicial. É a atuação expansiva do Judiciário frente à omissão do Legislativo ou à inércia do Executivo, determinando, por exemplo, a implementação de políticas públicas que garantam os direitos constitucionalmente assegurados. $O$ fenômeno do ativismo judicial é também objeto de críticas, havendo discussões quanto ao alcance dessa interferência do Poder Judiciário na seara dos demais poderes. Assim, o presente estudo buscou analisar os impactos do ativismo judicial na sociedade brasileira, abordando como ponto máximo a garantia do direito à educação básica que vem sendo defendida e assegurada pelos Tribunais em decorrência do novel modo de se aplicar o direito, que permite além de dizê-lo, de fato, efetivá-lo.
\end{abstract}

Palavras-chave: Ativismo judicial. Direito à educação básica. Direitos fundamentais. Separação dos Poderes.

\section{THE GUARANTEE OF THE RIGHT TO BASIC EDUCATION IN BRAZIL: JUDICIAL ACTIVISM AS AN ASSECURATORY MEASURE OF FUNDAMENTAL RIGHTS}

\begin{abstract}
The Judiciary has assumed a significant participation in the realization of fundamental rights. The exercise of the judicial function based on this attitude that goes beyond the typical functions attributed to the Judiciary can be termed as judicial activism. It is the expansive role of the Judiciary over the omission of the Legislative or the inertia of the Executive, determining, for example, the implementation of public policies that guarantee the rights constitutionally assured. The phenomenon of judicial activism is also the subject of criticism, and there are discussions about the extent of this interference by the Judiciary in the area of other powers. Thus, the present study sought to analyze the impacts of judicial activism in Brazilian society, addressing as a maximum the guarantee of the right to basic education that has been defended and ensured by the Courts as a result of the novel way of applying the right, which also allows To say, in effect, to effect it.
\end{abstract}

Keywords: Judicial activism. Right to basic education. Fundamental rights. Separation of Powers.

\section{INTRODUÇÃO}

Desde as primeiras aulas, seja de Teoria Geral do Estado ou de Direito Constitucional, os acadêmicos de Direito já se deparam com uma experiência inaugural sobre a teoria da Separação dos Poderes, esta que foi proposta pelo filósofo iluminista Montesquieu em sua obra "O Espírito das Leis", publicada em 1748, teoria adotada pela Constituição Federal brasileira de 1988 (CF/88) 
que ratifica a existência dos três Poderes da União: o Executivo, o Legislativo e o Judiciário; motivados pela independência e pela harmonia.

Nos moldes da tripartição, cada um dos poderes deve ser dotado de funções típicas ou primárias e de funções atípicas ou secundárias. Nessa ideia, o poder não estará concentrado nas mãos de apenas um organismo, mas distribuído, tripartido, havendo um controle mútuo para que um poder não se sobreponha ao outro, em um verdadeiro Sistema de Freios e Contrapesos "Checks and Balances" - eficaz e necessário.

Discorrer sobre o princípio da Separação dos Poderes torna-se pertinente, pois, o objeto de análise da presente pesquisa é o fenômeno do ativismo judicial, esse que intitula a ação expansiva do Poder Judiciário frente às demandas que lhes são propostas. E nesse sentido, por ser um modo de atuação do Judiciário que interfere na seara dos demais poderes, notadamente no campo das políticas públicas, restam críticas quanto a uma possível afronta ao princípio supracitado.

Para tratar do ativismo judicial de uma forma mais direcionada, a pesquisa em questão trouxe uma abordagem sobre a garantia do direito à educação básica no Brasil, tratando dos desafios enfrentados na educação básica no país, ainda que de forma não exaustiva, pois o tema se mostra bastante abrangente e rico em conteúdo de pesquisa.

O estudo teve como objetivo, no primeiro momento, fazer a localização do direito à educação básica no texto constitucional, após, uma apresentação do ativismo judicial abrangendo também as críticas que circundam esse fenômeno e, por fim, analisar algumas das decisões do Supremo Tribunal Federal (STF) voltadas à concretização do direito à educação básica, evidenciando, assim, a participação significativa do Poder Judiciário na efetivação de direitos fundamentais.

A metodologia utilizada foi o estudo de obras doutrinárias e artigos científicos sobre o assunto, meios que possibilitaram apurar o conhecimento acerca do tema, isto é, por contemplar um vasto campo de ideias, discussões e conteúdos que abrem um leque inesgotável de informações, o que demonstra a relevância da matéria que passará a ser exposta.

\section{DISCUSSÃO}

\section{O DIREITO À EDUCAÇÃO BÁSICA À LUZ DA CONSTITUIÇÃO FEDERAL DE 1988}

Consagra-se dentre os direitos sociais fundamentais previstos na Constituição Federal o direito à educação, um dos mais simbólicos direitos que carrega o verdadeiro sentido de ser fundamental. $O$ direito à educação se insere na categoria dos direitos sociais, sendo direitos de segunda geração, portanto, direitos de crédito, que comportam prestações estatais positivas.

Logo no art. 6으, caput, da Carta Magna o constituinte faz a primeira menção expressa no texto constitucional ao direito à educação. Bem mais adiante, no art. 205, se vê que a educação é considerada direito de todos e dever do Estado e da família, e que "será promovida e incentivada com a colaboração da sociedade, visando ao pleno desenvolvimento da pessoa, seu preparo para o exercício da cidadania e sua qualificação para o trabalho".

Discutir o tema da educação no Brasil é encarar uma realidade marcada por obstáculos ainda não superados. O acesso à escola ainda é um desafio, considerando que há no país um número alarmante de crianças e adolescentes ${ }^{1}$ que ainda estão sem o devido acesso às salas de

\footnotetext{
${ }^{1}$ A educação básica no Brasil deve ser garantida de forma obrigatória e gratuita às crianças e adolescentes dos 4 aos 17 anos de idade, assegurada inclusive sua oferta gratuita para todos os que a ela não tiveram acesso na idade própria (CF/88, art. 208, I).
} 
aulas $^{2}$. Isso demonstra que a diretriz da universalização do atendimento escolar prevista no Plano Nacional de Educação (PNE) ${ }^{3}$ ainda não foi cumprida, e que o princípio constitucional da igualdade de condições para o acesso e permanência na escola também está sendo negligenciado. (CF/88, art. 206, I).

Diante do cenário que traduz a dívida histórica que o Brasil possui com relação à educação, é evidente que surjam demandas atinentes à falta de acesso à escola, relativas também ao atendimento às condições dignas de educação oferecidas, alcançando, ainda, as próprias condições físicas do ambiente escolar, que em casos como os que serão analisados, há escolas no país que carecerem de estruturas físicas adequadas, o que compromete a qualidade do ensino, a segurança e a aprendizagem dos alunos.

O direito à educação tem sentido amplo, atingindo a esfera da própria dignidade humana, com valor que transcende os limites da sala de aula. A educação relaciona-se com o próprio desenvolvimento do homem, daí o seu caráter fundamental. A Declaração Universal dos Direitos Humanos de 1948, antes mesmo da promulgação da Constituição Cidadã, já dispunha: "A instrução será orientada no sentido do pleno desenvolvimento da personalidade humana e do fortalecimento do respeito pelos direitos do homem e pelas liberdades fundamentais" (Artigo $X X V I, 2)$.

No mesmo prisma, ratifica-se o entendimento com a ideia de Souza e Santana (2010) que consideram que o fundamento maior do direito à educação, previsto na Constituição Federal, encontra-se na Declaração Universal dos Direitos Humanos de 1948, direito que se pauta na doutrina e na jurisprudência tanto nacional quanto internacional, almejando um desenvolvimento humano adequado.

Nesse diapasão, não há como subtrair a fundamentalidade da qual o direito à educação está impregnado, direito subjetivo exigível, cujo dever de cumprimento é do Estado em consonância com os preceitos da Lei Maior, não podendo o poder estatal furtar-se do adimplemento das imposições constitucionais.

\section{O ATIVISMO JUDICIAL}

Sobre o ativismo judicial, nas palavras de Fernanda Priscila Ferreira Dantas, esse fenômeno "corresponde a uma participação mais efetiva do Poder Judiciário na concretização de preceitos constitucionais tidos como fundamentais pela Constituição de 88, provocando, por conseguinte, uma interferência mais significativa nos outros poderes" (DANTAS, 2016, p. 93).

Destarte, o ativismo judicial está intimamente relacionado à atitude proativa do Poder Judiciário, objetivando assegurar os direitos consagrados na Constituição. Cabe considerar, assim como pontua Dantas (2016), que essa atuação do judiciário não afeta a concepção forte e substancial de democracia, mas, de modo contrário, faz com que a democracia seja elevada ao seu grau máximo.

Para o professor Luís Roberto Barroso,

A idéia [sic] de ativismo judicial está associada a uma participação mais ampla e intensa do Judiciário na concretização dos valores e fins

\footnotetext{
${ }^{2}$ Levantamento feito pelo Todos pela Educação, mostra que em todo o país, 2,8 milhões de crianças e adolescentes, ou 6,2\% dos brasileiros entre 4 e 17 anos, ainda estão fora da escola. Informação disponível em: <https://educacao.uol.com.br/noticias/2016/01/19/brasil-tem-28-milhoes-de-criancas-e-adolescentes-fora-daescola.htm?cmpid=copiaecola $>$ Acesso em jun 2017.

${ }^{3}$ O Plano Nacional de Educação (PNE) fixa as diretrizes básicas, metas e estratégias para a política educacional no Brasil para o período de dez anos. O último plano foi aprovado em 2014 com vigência até 2024.
} 
constitucionais, com maior interferência no espaço de atuação dos outros dois Poderes. A postura ativista se manifesta por meio de diferentes condutas, que incluem: (i) a aplicação direta da Constituição a situações não expressamente contempladas em seu texto e independentemente de manifestação do legislador ordinário; (ii) a declaração de inconstitucionalidade de atos normativos emanados do legislador, com base em critérios menos rígidos que os de patente e ostensiva violação da Constituição; (iii) a imposição de condutas ou de abstenções ao Poder Público, notadamente em matéria de políticas públicas. (BARROSO, 2008, p.6).

Assim, é imperioso destacar que essa postura ativista do Judiciário, que se vale da primazia dos imperativos constitucionais para impor condutas ao Poder Público, alcança, significativamente, o campo das políticas públicas. Corroborando o fato de que o Judiciário "por meio de suas decisões tem determinado que a Administração Pública viabilize meios para a concretização de direitos fundamentais sociais, em determinados casos concretos que lhes são postos em apreço" (DANTAS, 2016, p. 93).

Como se verá adiante, o Supremo Tribunal Federal tem se posicionado de forma clara quanto à legitimidade de sua atuação, firmando precedentes. A conclusão é pela inexistência de violação ao princípio da Separação dos Poderes, no tocante à intervenção na implementação de políticas governamentais, sendo esse o ponto crítico que envolve o tema do ativismo judicial.

Adotando como exemplo o Agravo Regimental no Recurso Extraordinário com Agravo 639.337 4 na Ação Civil Pública ajuizada pelo Ministério Público do Estado de São Paulo, cujo objetivo era obrigar o município de São Paulo a matricular crianças na creche, verifica-se que

A discussão reside, sobremaneira, no princípio da Separação dos Poderes e na suposta ausência de legitimidade do Poder Judiciário em intervir na questão orçamentária. O STF aduziu, quando a essa questão, que a intervenção do Poder Judiciário, na implementação de políticas governamentais previstas e determinadas no texto constitucional objetiva neutralizar os efeitos lesivos e perversos que, provocados pela omissão estatal, nada mais traduzem senão em inaceitável insulto a direitos básicos que a própria Constituição Federal assegura à generalidade das pessoas. (DANTAS, 2016, p. 97-98).

Como crítica ao fenômeno em análise, Veronese e Rossetto (2017) consideram que através do ativismo judicial, o Poder Judiciário tem se reinventado e reivindicado mais poderes na sociedade, concluindo, ainda, que "com a prática do ativismo judicial, afronta-se o modelo de separação de poderes adotado pela Constituição" (VERONE; ROSSETTO, 2017, p. 259).

Por derradeiro, em uma conclusão crítica quanto ao fenômeno do ativismo judicial, cumpre destacar o posicionamento do professor Luís Roberto Barroso, no sentido de que

O ativismo judicial, até aqui, tem sido parte da solução, e não do problema.

Mas ele é um antibiótico poderoso, cujo uso deve ser eventual e

\footnotetext{
${ }^{4}$ STF - ARE: 639337 SP, Relator: Min. CELSO DE MELLO, Data de Julgamento: 21/06/2011, Data de Publicação: DJe-123 DIVULG 28/06/2011 PUBLIC 29/06/2011.
} 
controlado. Em dose excessiva, há risco de se morrer da cura. A expansão do Judiciário não deve desviar a atenção da real disfunção que aflige a democracia brasileira: a crise de representatividade, legitimidade e funcionalidade do Poder Legislativo. Precisamos de reforma política. E essa não pode ser feita por juízes. (BARROSO, 2008, p.19).

Sopesadas as críticas, resta ainda evidente que a atuação expansiva do Poder Judiciário na intenção de resguardar os preceitos constitucionais e garantir direitos fundamentais, contribui, em sua maioria, de forma positiva, desde que observados e respeitados certos limites. Isso significa que, por salvaguardar a Constituição frente à omissão dos outros dois Poderes, o Judiciário possui legitimidade, inexistindo a violação de princípios.

\section{ANÁLISE DE DECISÕES DO SUPREMO TRIBUNAL FEDERAL}

É dentro dessa esfera de necessidades não supridas e de direitos nada ou pouco efetivados, que surgem os clamores sociais às portas do Judiciário. Por meio de demandas individuais ou coletivas, se espera a concretude de direitos fundamentais, como o direito à educação básica do qual se discute no presente estudo.

Há situações que revelam o descaso dos demais Poderes. O Legislativo, que por vezes acaba se omitindo diante do ônus de disciplinar os fatos sociais quando os temas a serem legislados restam controvertidos; e o Executivo, que no desempenho da atividade administrativa deixa a desejar em matéria de planejamento e implementação de políticas públicas.

Diante da inadimplência dos demais Poderes, que traduz desrespeito à Constituição Federal, cabe ao Judiciário chamar para si a responsabilidade de fazer valer o que está disposto na Lei Maior. Referente ao tema que se discute, é plausível sustentar a ideia de que o

Supremo Tribunal Federal expressa a dimensão política da jurisdição constitucional concedida a essa Corte, que não pode esquivar-se diante da omissão estatal que redunda na ausência de concretização dos direitos sociais que, enquanto direitos de segunda geração, demandam prestações positivas do Estado. (DANTAS, 2016, p. 95).

Quanto à omissão da Administração pública no tocante à escassa concretização do direito à educação básica, notadamente o Judiciário tem chamado o Poder Executivo a implementar políticas públicas, como se verifica na ementa da decisão a seguir exposta:

AGRAVO REGIMENTAL EM RECURSO EXTRAORDINÁRIO COM AGRAVO. IMPLEMENTAÇÃO DE POLÍTICAS PÚBLICAS. DETERIORAÇÃO DAS INSTALAÇÕES DE INSTITUIÇÃO PÚBLICA DE ENSINO. CONSTRUÇÃO DE NOVA ESCOLA. POSSIBILIDADE. INEXISTÊNCIA DE VIOLAÇÃO AO PRINCÍPIO DA SEPARAÇÃO DOS PODERES. GARANTIA DO DIREITO À EDUCAÇÃO BÁSICA. PRECEDENTES. As duas Turmas do Supremo Tribunal Federal possuem entendimento de que é possível ao Judiciário, em situações excepcionais, determinar ao Poder Executivo a implementação de políticas públicas para garantir direitos constitucionalmente assegurados, a exemplo do direito ao acesso à educação básica, sem que isso implique ofensa ao princípio da separação dos Poderes. Precedentes. Agravo regimental a que 
se nega provimento. (STF - ARE: 761127 AP, Relator: Min. ROBERTO BARROSO, Data de Julgamento: 24/06/2014, Primeira Turma, Data de Publicação: ACÓRDÃO ELETRÔNICO DJe-158 DIVULG 15-08-2014 PUBLIC 18-08-2014)

No julgamento acima transcrito, em seu relatório, o Ministro Luís Roberto Barroso, expôs de forma clara e incisiva que a educação básica, dotada de status constitucional, qualifica-se como um direito social fundamental indisponível. Dessa forma, cabe, portanto, ao Estado o dever de prestar esse direito de forma regular e com qualidade.

O Ministro mencionou, ainda, que não basta o Estado assegurar às crianças e adolescentes apenas o acesso à matrícula escolar, mas que deve garantir também os meios necessários ao seu pleno desenvolvimento; o que inclui o fornecimento de condições estruturais e materiais mínimas do espaço físico onde a aprendizagem é desenvolvida. E que se o ambiente escolar não dispuser de tais condições mínimas isso estará inviabilizando a prerrogativa constitucional do direito à educação básica.

Ainda sobre o ARE 761.127, decidiu-se que

o Supremo Tribunal Federal possui o entendimento no sentido de reconhecer ao Judiciário a possibilidade de, em situações excepcionais, determinar ao Poder Executivo a implementação de políticas públicas a fim de garantir direitos constitucionalmente assegurados, a exemplo do direito ao acesso à educação básica, sem que isso implique ofensa ao princípio da separação dos Poderes.

Em julgamento de semelhante teor - Agravo Regimental em Recurso Extraordinário com Agravo 845.392/RS, Relator, Ministro Luís Roberto Barroso ${ }^{5}$-, o Supremo ratificou o entendimento de que inexiste violação ao princípio da Separação dos Poderes, e que a jurisprudência do STF é firme no sentido de que, em casos emergenciais, ante a inércia ou morosidade da Administração, o Judiciário pode se manifestar adotando medidas para assegurar os direitos fundamentais.

Analisando outra decisão do $\mathrm{STF}^{6}$, na interpretação de Dantas, a Corte entende que

mesmo reconhecendo que o Poder legislativo e Executivo detêm a prerrogativa primária de implementar as políticas públicas, é plenamente possível legítimo [sic] que o Poder judiciário intervenha nas políticas públicas diante da inadimplência ilegal dos órgãos estatais, cuja omissão compromete e impede qualquer eficácia aos direitos impregnados de fundamentalidade pela CF. (DANTAS, 2016, p. 94).

Por fim, se faz evidente que o caráter de ser fundamental do direito à educação básica é plenamente reconhecido pelo STF, conforme se verifica em suas decisões. E por possuir essa carga

\footnotetext{
${ }^{5}$ STF - ARE: 845392 RS, Relator: Min. ROBERTO BARROSO, Data de Julgamento: 09/12/2014, Primeira Turma, Data de Publicação: ACÓRDÃO ELETRÔNICO DJe-021 DIVULG 30-01-2015 PUBLIC 02-02-2015.

${ }^{6}$ STF - RE-AgR: 410715 SP, Relator: Min. CELSO DE MELLO, Data de Julgamento: 22/11/2005, Segunda Turma, Data de Publicação: DJ 03-02-2006 PP-00076 EMENT VOL-02219-08 PP-01529 RIP v. 7, n. 35, 2006, p. 291-300.
} 
demasiadamente valorosa, o Poder Judiciário se vê autorizado a adotar provimentos jurisdicionais a fim de concretizar as prerrogativas constitucionais.

\section{CONCLUSÃO}

Partindo para as considerações finais e sintetizando os conteúdos abordados, cumpre destacar que através da presente pesquisa foi possível certificar a importância do direito à educação básica, tendo em vista ser um dos direitos sociais fundamentais consagrados na Constituição Federal, e que exige prestações positivas do Estado para a sua efetivação.

Da análise do fenômeno do ativismo judicial, restou claro o entendimento de que a postura proativa do Poder Judiciário não viola o princípio da Separação dos Poderes e que está plenamente revestida de legitimidade, pois através dessa atuação pretende-se assegurar as prerrogativas constitucionais frente à inércia, omissão ou morosidade dos outros dois Poderes.

As decisões do Supremo Tribunal Federal evidenciaram o posicionamento de que é plenamente possível e legítimo que o Judiciário intervenha, em casos excepcionais, nas políticas públicas diante da inadimplência ilegal dos órgãos estatais, cuja omissão compromete e impede qualquer eficácia aos direitos fundamentais.

Desse modo, a conclusão é de que, até o momento, o ativismo judicial tem sido parte da solução e não do problema, mas isso não isenta o Poder Judiciário de observar os limites, agindo na eventualidade e com controle, para que não ocorram excessos capazes de comprometer a ordem democrática do país.

\section{REFERÊNCIAS}

BARROSO, Luís Roberto. Judicialização, Ativismo Judicial e Legitimidade Democrática. Disponível em: <http://www.cnj.jus.br/eadcnj/mod/resource/view.php?id=47743> Acesso em jul 2017.

BRASIL. Presidência da República. Constituição da República Federativa do Brasil. Disponível em: <http://www.planalto.gov.br/ccivil_03/constituicao/constituicaocompilado.htm>. Acesso em jul 2017.

BRASIL. Supremo Tribunal Federal. Agravo Regimental no Recurso Extraordinário Com Agravo no 845392. Agravante: Estado do Rio Grande do Sul. Agravado: Ministério Público do Estado do Rio Grande do Sul. Relator: Min. Roberto Barroso. Rio Grande do Sul, RS, 09 de dezembro de 2014. Implementação de Políticas Públicas. Instalações de Instituição Pública de Ensino em Condições Precárias. Disponível em: <https://stf.jusbrasil.com.br/jurisprudencia/25352075/agregno-recurso-extraordinario-com-agravo-are-845392-rs-stf>. Acesso em ago 2017.

BRASIL. Supremo Tribunal Federal. Agravo Regimental no Recurso Extraordinário Com Agravo no 639337. Agravante: Município de São Paulo. Agravado: Ministério Público do Estado de São Paulo. Relator: Min. Celso de Mello. São Paulo, SP, 21 de junho de 2011. Criança de até cinco anos de idade. Atendimento em creche e em pré-escola. Disponível em: <https://stf.jusbrasil.com.br/jurisprudencia/22932599/recurso-extraordinario-com-agravo-are639337-sp-stf $>$. Acesso em ago 2017.

BRASIL. Supremo Tribunal Federal. Agravo Regimental no Recurso Extraordinário Com Agravo no 761127. Agravante: Estado do Amapá. Agravado: Ministério Público do Estado do Amapá. Relator: Min. Roberto Barroso. Amapá, AP, 24 de junho de 2014. Implementação de políticas públicas. 
Deterioração das instalações de instituição pública de ensino. Disponível em: <https://stf.jusbrasil.com.br/jurisprudencia/25244125/agreg-no-recurso-extraordinario-comagravo-are-761127-ap-stf>. Acesso em ago 2017.

BRASIL. Supremo Tribunal Federal. Agravo Regimental no Recurso Extraordinário no 410715. Agravante: Município de Santo André. Agravado: Ministério Público do Estado de São Paulo. Relator: Min. Celso de Mello. São Paulo, SP, 22 de novembro de 2005. Criança de até seis anos de idade - atendimento em creche e em pré-escola - educação infantil. Disponível em: $<$ https://stf.jusbrasil.com.br/jurisprudencia/762513/agregno-recurso-extraordinario-reagr410715-sp>. Acesso em ago 2017.

DANTAS, Fernanda Priscila Ferreira. Direitos Sociais no Brasil: desafios e mecanismos para a sua concretização. Curitiba: Juruá, 2016.

ONU. Declaração Universal dos Direitos Humanos. Disponível em: <http://www.onu.org.br/img/2014/09/DUDH.pdf> Acesso em ago 2017.

SOUZA, Marcelle. Brasil tem 2,8 milhões de crianças e adolescentes fora da escola. Disponível em: $\quad$ https://educacao.uol.com.br/noticias/2016/01/19/brasil-tem-28-milhoes-de-criancas-eadolescentes-fora-da-escola.htm?cmpid=copiaecola> Acesso em jul 2017.

SOUZA, Mércia Cardoso De; SANTANA, Jacira Maria Augusto Moreira Pavão. O direito à educação no ordenamento constitucional brasileiro. In: Âmbito Jurídico, Rio Grande, XIII, n. 74, mar 2010. Disponível em: <http://www.ambitojuridico.com.br/site/index.php?n_link=revista_artigos_leitura\&artigo_id=7368> Acesso em ago 2017.

VERONESE, Eduardo Rafael Petry; ROSSETTO, Geralda Magella de Faria. Dignidade da Pessoa Humana e Ativismo Judicial: Além da "História" Interpretativa - do que o intérprete requer saber no processo decisional. In: VERONESE, Josiane Rose Petry; OLIVEIRA, Olga Maria B. Aguiar de (Orgs). Direito, Justiça e Fraternidade. Rio de Janeiro: Lumen Juris, 2017. 